\section{LA CREATIVIDAD COMO RECURSO ECONÓMICO: APROXIMACIONES AL ESTUDIO DEL DISEÑO INDEPENDIENTE COMO ESTRATEGIA DE INSERCIÓN DE JÓVENES EN LA CIUDAD DE BUENOS AIRES.}

\author{
CREATIVITY AS AN ECONOMIC RESOURCE: APPROACHES TO THE \\ STUDY OF INDEPENDENT DESIGN AS AN INCLUSION STRATEGY OF \\ YOUNG PEOPLE IN BUENOS AIRES ${ }^{1}$
}

\section{María Eugenia Correa ${ }^{2}$}

Palabras clave: Jóvenes diseñadores independientes, Producción cultural, Estrategias de inserción laboral, Construcción identitaria.

Keywords: young independent designers, cultural production, work inclusion strategies, identity construction.

Avances de un trabajo de investigación realizado en el marco de una beca doctoral de CONICET Posgrado Tipo I (2007-2010) y Beca doctoral CONICET Tipo II (2010-2012). Esta investigación formó parte de la tesis de Maestría en Sociología de la Cultura y Análisis cultural (2009, IDAES-UNSAM), bajo el título "El fenómeno del diseño independiente en la Ciudad de Buenos Aires: análisis de la conformación de un nuevo trabajador cultural en la escena local.", bajo la dirección de la Dra. Ana Wortman.

\section{Resumen}

A partir de la crisis del 2001 en Argentina, y específicamente en la Ciudad de Buenos Aires, se han desarrollado diversos emprendimientos autogestionados vinculados a la producción de diseño, dando lugar a la participación de numerosos jóvenes en la estructura productiva.

En este entramado se configuran los jóvenes diseñadores independientes, que combinan estrategias económicas productivas con producciones culturales artísticas, dando forma a objetos que portan una estética singular.

Interesa conocer la modalidad de inserción de estos jóvenes diseñadores por
Páginas $35-52$
1. Traducción de Gabriela Guerrero Revisión Centro de Traducción del Instituto de Idiomas UAM.

2. Lic. en Sociología (UBA) / Mg. Sociología de la Cultura (IDAESUNSAM), Docente de la Facultad de Ciencias Sociales, UBA. Becaria doctoral CONICET, Instituto de Investigaciones Gino Germani. Facultad de Ciencias Sociales, UBA. eugeniacorrea@ mail.fsoc.uba.ar

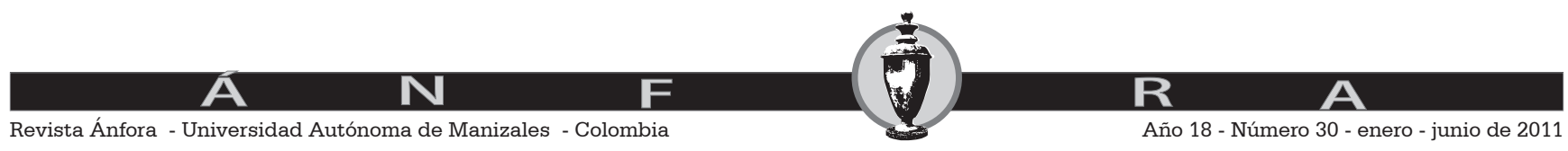


su impacto en el campo cultural y en la propia cotidianidad, al interior de una cultura visual posmoderna, en la cual el diseño interviene los objetos brindándoles valor simbólico incorporado a la vida cotidiana. Además se busca comprender el modo en que esta práctica construye estilos de vida y configura identidades, apelando a consumos individualizados en torno a los bienes de diseño.

Se presentarán en este trabajo las recientes conclusiones de la investigación realizada.

\begin{abstract}
This paper aims at presenting a research project about how diverse self-management startups related to production design have been developed since 2001 based on Argentina's crisis, particularly in Buenos Aires. This situation generated the participation of young people in the productive structure.

Within this framework, young independent designers combine economic productive strategies with cultural artistic productions, giving to objects a unique esthetics.

It is interesting to know the inclusion modality of those young designers because of the impact in the cultural field and daily life. In other words, it is their inclusion into a visual postmodern culture, in which design intervenes objects adding them a symbolic value when included in daily life. Furthermore, it pretends to understand the way this practice builds lifestyles, identities based on the recognition of individual purchases around design goods. Finally, recent conclusions about this project will be presented.
\end{abstract}

\title{
Introducción
}

En los últimos años, entre fines de los '90 y principios del nuevo milenio, la Argentina se vio inmersa en profundas transformaciones, tanto en el plano político, como en el económico, en lo social como en lo cultural, consecuencia de una década trazada por la apertura económica internacional y la aplicación de sucesivas políticas neoliberales que darían lugar a un deterioro de la economía local, así como políticas de desregulación y flexibilización del mercado de trabajo, que generarían un alto nivel de desempleo, afectando a una significativa franja de la población, dentro de la cual el segmento juvenil sería el más desfavorecido por esta situación.

De este modo, la década del '90 dio lugar a la implementación de políticas económicas de concentración de capitales, que sentarían las bases de un modelo económico y social excluyente, generando por consecuencia una creciente desintegración en relación a la estructura socio-productiva, de numerosos actores provenientes de los sectores medios y bajos. (Beccaria y López, 1997)

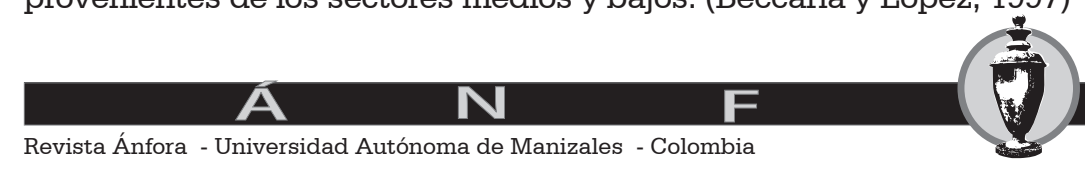


Como contrapartida, este modelo promovería desde una línea informal nuevas modalidades de integración, basadas principalmente en la adaptación y supervivencia económica y social (Kessler, 2003; Lvovich, 2003). Esto es, si bien el período de decadencia económica y social de los '90 generó instancias de pauperización y exclusión entre numerosos actores, por otra parte a partir del período de crisis del 2001 se comenzaron a generar nuevas modalidades de participación en el espacio social, dando lugar a redes y espacios de acción productiva, fomentados en torno a los sectores medios (Svampa, 2005).

En este sentido la autora Maristella Svampa plantea que "frente al empobrecimiento, los individuos se vieron en la necesidad de redefinir los marcos sociales y culturales de su experiencia." (2005: 143). En este punto la experiencia de la crisis del 2001 generó una instancia de movilizaciones sociales que puso en relieve una necesidad de expresión popular en la escena pública.

Esta emergencia de nuevos modos de participación tanto en la escena social como en la estructura productiva dio lugar a la configuración de nuevos actores en el espacio público. Si bien el 2001 marcó un período de movilizaciones en torno a lo político, podemos decir que actuó a su vez como disparador de múltiples instancias productivas, muchas de ellas organizadas desde la autogestión ${ }^{3}$

De esta manera, podemos observar como un ejemplo de estas configuraciones productivas desarrolladas en los últimos años, la emergencia de numerosos jóvenes diseñadores que han 'irrumpido' en el mercado de bienes y servicios, alcanzando una visibilidad pública notable. La presencia de estos jóvenes en la estructura productiva -en muchos casos desarrollando trabajos de manera informal- da cuenta de un fenómeno en crecimiento que refleja, por un lado, nuevas modalidades de producción, vinculadas al desarrollo de empleos propios de una economía creativa, y por otro, la configuración de nuevas prácticas de consumo, ligadas a la incorporación de bienes mayormente individualizados, adoptados en un contexto de construcción de estilos de vida a través de los consumos, al interior del cual el diseño ha pasado a tener un rol preponderante.

Así, muchos de estos jóvenes diseñadores han nacido a la luz de la crisis del 2001, impulsando a través de sus creaciones y producciones artísticas una estrategia de inserción, al interior de un contexto de desempleo y escasa participación en el mercado laboral formal en relación a los jóvenes, quienes justamente componen el segmento de edad con mayor dificultad al momento de insertarse laboralmente.

De este modo, este trabajo se propone dar cuenta de las características que adopta la práctica del diseño en tanto estrategia de inserción autogestionada por numerosos actores jóvenes que han apelado al diseño como búsqueda de desarrollo de emprendimientos creativos y productivos generadores de nuevos espacios de participación en la estructura socio-productiva.
3 La autogestión constituye una estrategia difundida en el contexto de crisis de 2001 en nuestro país, adoptada por numerosos actores tanto en el plano político (ej: asambleas barriales, movimientos sociales) como en el económico, en el caso de actores que han apelado a proyectos de tipo micro-emprendimiento o el caso de la autogestión de fábricas recuperadas, así como en el plano artístico o cultural, como los colectivos de arte urbano o artistas independientes.

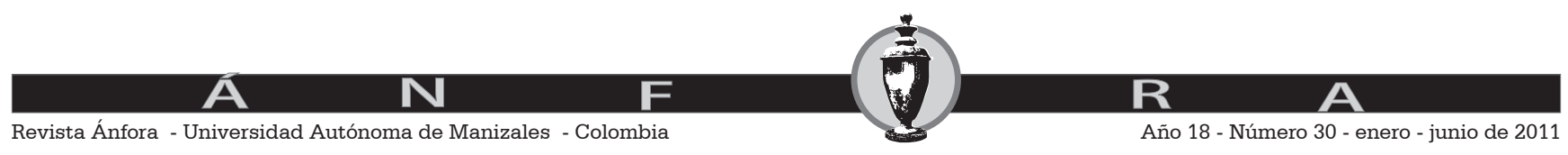




\section{Metodología abordada}

Ahora bien, en cuanto a la metodología utilizada para desarrollar esta investigación, la misma se encuentra basada en una estrategia de índole cualitativa, con el fin de conocer en profundidad las formas de producción, inserción y participación de los jóvenes diseñadores, focalizando en sus propias percepciones en relación a su desarrollo social y productivo en tanto productores/ emprendedores. Para alcanzar tal fin se han aplicado entrevistas en profundidad y observaciones participantes con el propósito de producir datos desde un análisis de su propio contexto de acción. De esta manera, es posible conocer e indagar la forma en que los jóvenes diseñadores entrevistados trabajan, la manera en que confeccionan sus productos, los distribuyen y los circulan en el mercado, conformando un núcleo de producción altamente creativo, vinculado al diseño, desde la autogestión.

En cuanto a las entrevistas realizadas, las mismas corresponden a quince actores que participan activamente en el mercado como diseñadores independientes. Los mismos se caracterizan por conformar un emprendimiento de tipo independiente, iniciado a modo de micro-emprendimiento, al mismo tiempo que plantean una modalidad de participación estratégica en tanto que apelan a sus creatividades al momento de producir y así han podido generar un modo de incorporar sus productos a la oferta del mercado de manera original, apostando a formatos novedosos, combinando creación estética con instancias subjetivas como destrezas y habilidades plasmadas en la producción, en su mayoría tratándose de productos creados a partir de una técnica artesanal $^{4}$, producidos manualmente, buscando alejarse de esta manera de los productos encontrados en el mercado formal, de shopping, esto es, productos masivos y seriados.

Al momento de comenzar el trabajo de campo se ha trabajado en base a ferias locales como: Feria Puro Diseño, Feria El Dorrego, ferias de diseño independiente de la plaza Serrano en el barrio de Palermo, ferias de diseño en el barrio de San Telmo (entendido como un nuevo núcleo urbano de diseño, además del barrio de Palermo) y demás ferias de diseñadores en las cuales confluyen este tipo de diseñadores artísticos, a partir de las cuales se establecieron contactos con muchos de estos jóvenes diseñadores, buscando indagar estrategias de producción y acción.

En este punto debemos destacar que esta creciente producción de bienes de diseño instalada en la escena pública a través de la visibilidad de estas ferias -de diseño independiente-, no representa netamente el despliegue de una nueva generación de jóvenes diseñadores abocados a alimentar el mercado con sus creaciones de diseño, sino mucho más que eso, esto es, componen un universo conformado por diseñadores, artistas, escultores, pintores, arquitectos, decoradores, o simplemente sujetos "creativos" que ven en el diseño de objetos una nueva veta artística como posibilidad de inserción económica y laboral que refleja al mismo tiempo una configuración cultural en torno a la producción de diseño (Correa, 2007).
4 Con respecto a la instancia artesanal-industrial, en cuanto al diseño, podemos decir que, si bien éste presenta sus inicios al interior del perídodo histórico de la Revolución Industrial, a mediados del siglo XVIII, adoptado e incorporado a la producción industrial, con el tiempo, al diversificarse el diseño, éste se ha vuelto una práctica adoptada por una diversidad de disciplinas, áreas y espacios de producción, siendo aplicado tanto desde una técnica artesanal como industrial.

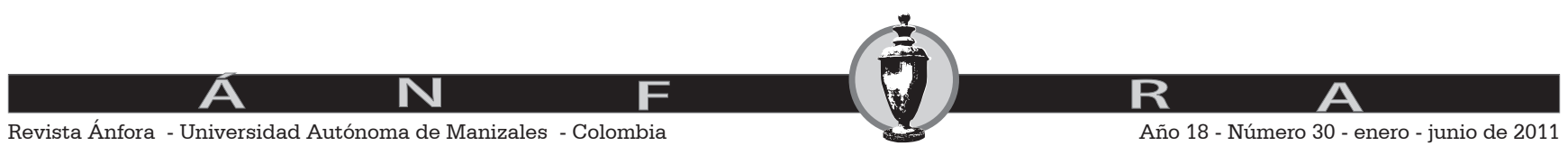




\section{El fenómeno del Diseño independiente en Argentina}

El escenario político, económico y social visible en la Argentina de la década del '90 se ha sostenido y configurado en un marco de implementación de políticas de Estado que, entre otros efectos, dieron lugar a una apertura comercial a nivel mundial, a partir de la implementación de políticas neoliberales que actuaron en función de una mayor participación del mercado externo y de capitales extranjeros en nuestro país.

Esta situación podemos decir que condujo a precipitar, en términos económicos, la producción nacional, dando lugar a un decrecimiento en la producción de bienes nacionales, y al mismo tiempo una ausencia de competitividad con los productos extranjeros, con lo cual la afluencia de bienes importados no sólo se volvió cuantitativamente significativa, sino que la misma de alguna manera monopolizó el mercado de bienes y servicios en el país, generando un deterioro tanto en la producción de bienes nacionales como así también en sus propios consumos.

La nueva conformación de los consumos, principalmente de los sectores medios y medios altos, se encontraba definida por la entrada de bienes manufacturados provenientes del exterior. La incorporación gradual de este tipo de bienes al hogar no sólo daría lugar a un privilegiado posicionamiento de los mismos en el mercado de bienes y servicios, sino que sentaría al mismo tiempo las bases de los nuevos consumos de bienes, vinculados a la oferta de bienes y servicios transnacionales en un sentido global.

Esta dinámica 'global' económica, justamente tiene sus connotaciones en el plano cultural, en las vivencias y la propia experiencia en la vida cotidiana. Esto es, tal como plantea Renato Ortiz, "la vivencia misma se vuelve mundializada" (Ortiz, 1997: 17). En este sentido, vemos la significativa presencia de las marcas mundiales en la vida cotidiana, como parte de esta misma dinámica global, produciendo justamente marcas en la propia vida diaria, marcas en el sujeto, marcas que provienen de esta nueva dinámica que lo envuelve y de la cual no puede estar exento. De este modo, y citando nuevamente a Ortiz, podemos pensar en esta dinámica de la economía global y en su puesta en escena en la propia cotidianidad, a modo envolvente, casi invasivo, tal como plantea este autor "Marlboro, Euro Disney, fast food, Hollywood, chocolates, aviones, computadoras, sólo son trazos visibles de su presencia envolvente. Ellos invaden nuestras vidas, nos cercan o nos liberan y forman parte del mobiliario de nuestro cotidiano. El planeta se encarna así en nuestra existencia, modificando nuestros hábitos, nuestros comportamientos, nuestros valores". (Ortiz, 1997: 19)

Podemos decir entonces que en este contexto global incipiente se configuraba en los '90 un mercado cuya oferta principal de bienes y servicios provenía del extranjero, generando un entramado de bienes y servicios transnacionales. Se reestructuraba de esta manera por consecuencia el mercado local, el mercado de bienes y servicios nacionales, afectando a su vez la producción de la industria nacional, con un alto impacto en la capacidad de absorción de

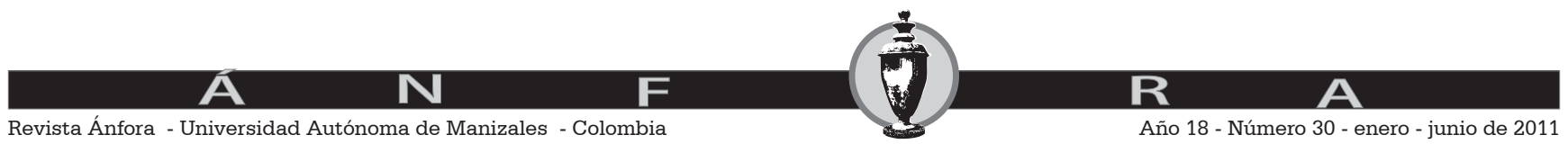


trabajadores al mercado de trabajo formal, reflejando una notable disminución del empleo formal en esta década.

Como planteáramos anteriormente, en este contexto de disminución de producción en el sector manufacturero, los productos manufacturados que eran objeto de consumo en el mercado interno provenían en su mayoría del exterior. A su vez, esta creciente afluencia de productos extranjeros, visible en los '90, se vio acompañada por un imaginario social de accesibilidad a determinados bienes y servicios internacionales que tanto el proceso de globalización, como la situación económica de convertibilidad, y las nuevas modalidades de consumo generadas en torno a la misma, contribuyeron a gestar y a formar en los sujetos.

Este cambio en la cartografía cultural, en la conformación de estilos de vida mayormente individualizados, vinculados a consumos diferenciados y a nuevas prácticas culturales desplegadas en la escena social, acompañó la gestación de una nueva estética reflejada en los consumos. Esta puesta en escena de nuevas prácticas culturales alojó a la producción de diseño contemporáneo que comenzó a desplegarse en el mercado en la década de los '90 en la Argentina. Si bien en este período se importaban bienes de diseño producidos en el mercado internacional, un mercado que privilegiaba la investigación y el desarrollo en la producción, con el tiempo, entre fines del 2001 y en el transcurso del 2002, en un contexto de crisis económica y social, fin de la política de convertibilidad y en un marco de devaluación del peso nacional, se daría lugar a una recuperación de la producción local de bienes, dada, entre otras instancias, por el costo económico que implicada entonces la posibilidad de importar. En este marco, la confección de bienes a partir del desarrollo del diseño en su proceso productivo habría se instalarse en el mercado local, y en los imaginarios sociales, alcanzando cada vez mayor protagonismo.

En este sentido cabe preguntarnos por la eficacia simbólica del término 'diseño', la impronta estética que acompaña la producción de bienes, indagando si esta dimensión simbólica que predomina actualmente al interior de la cultura visual que nos rodea, es obra del diseño o si por el contrario esta dimensión visual de la cultura de la imagen ha dado lugar a la centralidad del diseño en la producción y construcción cotidiana. Cuestión que sugiere una reflexión que trasciende nuestro trabajo, pero que de alguna manera lo atraviesa.

\section{El diseño como práctica 'autogestionada'}

Al introducirnos en el análisis de las entrevistas realizadas, una cuestión que aparece significativamente en todas las entrevistas es la referente a los inicios de los emprendimientos de estos jóvenes. Estos quince entrevistados tienen en común sus inicios en el diseño a partir de la crisis del 2001, momento que dio lugar a la proliferación de múltiples emprendimientos económicos y laborales. Es decir que este período actuó, a modo de 'bisagra', como un

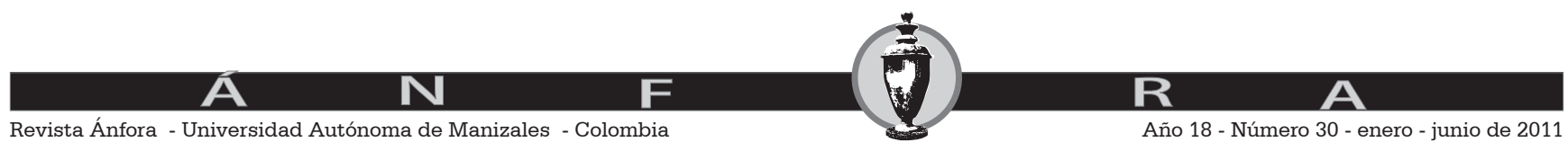


referente significativo de cambio en lo personal, sea consecuencia de una situación de desempleo, de necesidad de cambio de trabajo, de vincularse a algún emprendimiento creativo como modo de autorrealización personal, o como un modo de generar nuevos ingresos apostando a un proyecto propio, de tipo independiente, según se manifiesta en las diferentes entrevistas (Correa, 2009).

Tanto en relación a sus formaciones como a sus experiencias o trayectorias vinculadas a su inserción laboral, estos proyectos se enmarcaban simbólicamente en un plano de lo conocido o lo deseado, cargándolos de un sentido subjetivo experimental, que condujo a estos actores a apostar por la producción creativa, en este caso vinculada al diseño de bienes de uso cotidiano ${ }^{5}$ . Los mismos serían realizados, en algunos casos, en función de un proyecto económico, con un fin comercial, en otros como búsqueda de un nuevo emprendimiento productivo laboral, con énfasis en lo creativo, y en otros, más bien como producto de una actividad placentera, complementaria, que acompañaría a alguna ocupación principal, generando una nueva fuente de ingresos.

La creación de productos denominados "de diseño", de acuerdo a estos casos, no nació como tal, sino que comenzó más bien como una exploración de materiales, técnicas, hasta llegar a la realización de creaciones propias de productos diferentes a los ofrecido en el mercado, con un formato más bien artesanal, de tipo manual. El relato de un entrevistado (Gustavo, 36 años, arquitecto, diseñador de objetos en cemento, creador del emprendimiento "ConcretoArt") da cuenta de estos inicios:

Por ahí en los '90 empezaron a aparecer estudios muy grandes de arquitectura que empezaron como a meterse, ya era muy difícil sostener trabajo continuo como profesional independiente sin tener un estudio grande, sin tener capital para invertir, y etc., etc. Entonces empezó a mermar el trabajo y dije bueno, necesito hacer algo urgente y también coincide con una crisis mía personal, entonces me salvó en algún sentido también anímicamente, porque yo estaba en un Estado de depresión muy groso, económico también, en el '99, y entonces me puse a probar, a intentar con el material, a probar, empecé desarrollando bases para velas, que era, digamos, empezaba a aparecer en el mercado, se había puesto muy de moda la vela, y entendí que hacían falta accesorios para velas, y hacían falta complementos y empecé a desarrollar una línea de bases para velas que era lo más básico, y digo empiezo con algo de mucha demanda y después empiezo a desarrollar con el tiempo, voy a empezar a investigar el material y a desarrollar otros objetos. (Gustavo, arquitecto)
5 En esta investigación nos centramos en el análisis de diseñadores que confeccionan productos de uso cotidiano, como ser, mobiliario, luminarias, elementos de cocina, vajilla, elementos de baño (jaboneras, cestos, toalleros, etc.), elementos decorativos de interiores (portavelas, macetas, cuencos, etc), o accesorios textiles (de uso hogareño como almohadones, puffs, o de uso personal, como prendedores, collares, pulseras, entre otros). Esta producción de diseño se enmarca mayoritariamente en una técnica de trabajo artesanal, la cual puede combinarse con una modalidad industrial. Esta artesanalidad que prima en la producción da cuenta de un modelo productivo subjetivo, que como veremos más adelante, traduce un vínculo identitario entre el creador y su objeto.

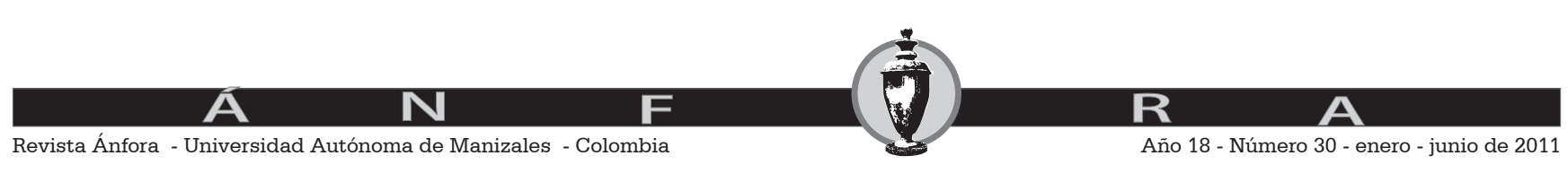


Así, el entrevistado relata sus inicios en este nuevo emprendimiento, en el cual, daba un giro a su profesión. En este proyecto comenzó a trabajar el cemento como material para crear objetos, y a partir de una búsqueda, exploración y varias pruebas de ensayo y error, comenzó a generar una línea de objetos basados en este material, que comenzó a vender en pleno período de transición, recién en el año 2002:

Había Estado casi dos años dedicado a full en el taller, en el emprendimiento, y de golpe me caí, quedó ahí, me quedé mirando el techo diciendo "qué pasa", porque en el país estaba todo muy oscuro, no sabías qué iba a pasar, estaba tremendo, no había futuro, no había perspectiva, no había nada. A mucha gente lo agarró mal parado, a mucha gente no, había gente que tenía un emprendimiento y más o menos lo pudieron sostener, otros se cayeron, y bueno yo estuve entre los que se cayeron, totalmente fue, que perdí todo. Y bueno, estuve seis meses en el 2002 que inclusive evalué la posibilidad de irme afuera y digo bueno, empiezo todo para irme. Y a mediados del 2002 ya desesperado me llaman por teléfono de una distribuidora que necesitaba productos nacionales. (Gustavo)

Este entrevistado inicia así un emprendimiento vinculado al diseño de objetos para el hogar realizados en cemento, el cual implica en sus propios términos "un proyecto que surge a partir de la necesidad, de la desesperación", dejando en claro la situación que dio origen y bajo la cual fue concebida la idea de llevar adelante este proyecto personal.

A su vez, una entrevistada (Silvina, 30 años, creadora de un proyecto independiente de producción de accesorios en tela reciclada), plantea el inicio de su propio emprendimiento vinculado a la situación económica y social que dio lugar a la crisis del 2001 en el país:

Empecé a estudiar [diseño de indumentaria] en la UBA en 1996, cuando éramos dos gatos locos, la carrera era muy nueva (...) Estudiar esto no brindaba un panorama muy alentador, porque era todo importado. Además los profesores no eran diseñadores, sino que eran arquitectos. Ninguno trabajaba de esto ni vivía de esto. Era todo chino y las clases eran bastante redundantes porque comprábamos remeras por un peso. (...) Me empezó a agarrar crisis de no querer trabajar en producto,

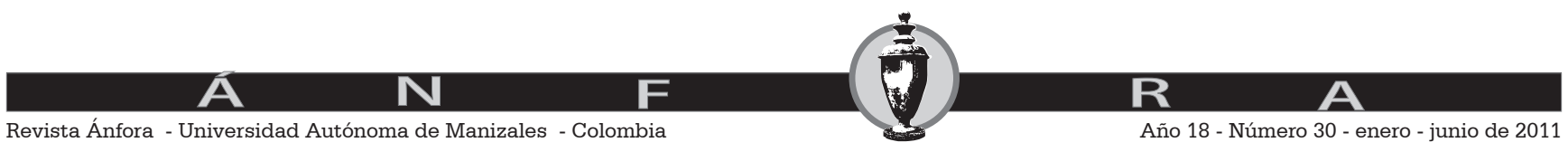


no querer trabajar en empresas. En ese momento no se hacía nada acá y todo era copiar. No había como ahora esta explosión de diseño de autor y de gente que trabaja independiente. Yo empecé la carrera en el 96 y esta crisis me agarró en el 2001, justo cuando colapsa todo acá en Argentina, y colapsé yo y dije no. Esto no va. (Silvina)

En este relato la entrevistada da cuenta de la situación de desaliento que le transmitía estudiar una carrera de diseño en un marco en el cual la producción nacional casi no tenía lugar en el país. Esta idea es la que junto a su situación laboral en una empresa de telefonía móvil (la cual no satisfacía sus expectativas) y la situación de crisis en el 2001, la instaron a reflexionar sobre su situación personal, sus deseos y sobre esta situación de malestar social, de crisis social que directamente sentía que repercutía en ella:

Bueno, es que se alineó todo. Fue todo un combo muy explosivo. También coincidía con que yo tenía 23, 24 años, sin ganas de tener un trabajo de 8 horas, con el país colapsado. Con miedo y a la vez diciendo bueno, tengo toda la energía para hacer lo que quiera. Acá estaba todo mal, ¿que más mal podía estar? Estaba todo mal y a su vez me hizo mucho clic caminar y ver que desechaban tantas cosas. Pensé que éramos muchas personas en el mundo, generando mucha basura. Y eso era materia prima para un montón de gente. Era una materia prima importante. No podía entender como eso no seguía un círculo en un ecosistema. Eso tenía que ser materia prima de alguien. Y eso me motivaba, yo quería hacer algo con deshecho. Ahí empecé a hacer de eso un hábito. Iba a buscar, algo que al principio fue como casualidad, se daba como hábito. (Silvina)

Así su actividad comenzó a tomar un rumbo: el del reciclado de materia textil (telas desechadas de todo tipo y color) volviéndolo piezas de joyería textil y accesorios textiles (como almohadones y puffs), una actividad que si bien ya era desarrollada en otros países, en la Argentina era ciertamente innovadora.

Otro entrevistado (Alfio, 31 años, diseñador industrial y artista) también plantea el inicio de su emprendimiento personal vinculado al arte y al diseño en articulación con el momento de la crisis del 2001:

E: ¿Cuáles fueron tus trabajos anteriores?

A: Trabajé de muchas cosas (...) Laburé de ambientador,

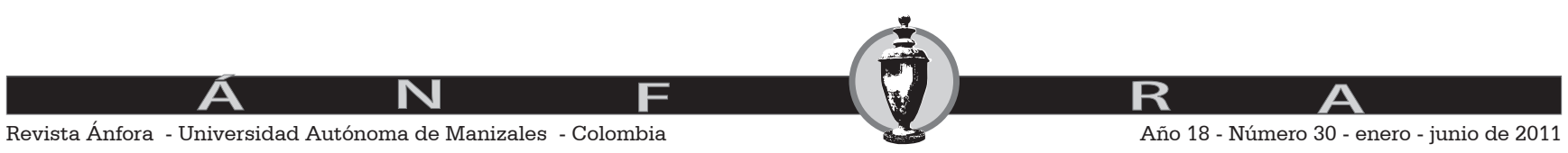


decorador, iluminador, montajista, laburé también en una empresa de controles satelitales. Laburé en Telecom., hasta que en un momento, después del 2001, después del quilombo del 2000, 2001, dije, no loco, esto no va más...

E: ¿Qué no iba más?

A: Estar siendo empleado, después de haber laburado mucho tiempo, en esta empresa de Control satelital, 4 años, y que todo se vino a pique y digo: estuve 4 años laburando, dando mi tiempo a una empresa con una misión que no era la mía, por que no era lo mío, y con todo el quilombo no había podido ahorrar dinero, no había podido hacer arte, porque estaba laburando, y dije tengo que empezar a construir mi propio negocio, hacer mi propia vida con mis intereses, aunque sea difícil, aunque pueda pasar hambre y momentos difíciles. $Y$ empezar a ver cuál era mi misión, qué era lo que realmente quería. Si era realmente estar en una empresa trabajando 12 horas o era hacer algo por los demás. En un momento dije basta de toda esta farsa de ser empleado...

Estas entrevistas nos permiten comprender y reflexionar acerca de cómo un momento de crisis, de necesidades, de cambios como lo fue el período del 2001 puede significar el replanteo de un modo de vida. Esto es, la búsqueda de una posibilidad de desarrollo personal vinculado al desarrollo de emprendimientos creativos parece haber configurado un camino a seguir a partir de este momento. De este modo, los relatos permiten observar de qué manera la creatividad -comprendiendo por dimensión creativa una capacidad intuitiva, reflexiva y subjetiva de transformación y creación simbólica y material- ha permitido llevar adelante un emprendimiento que pasaría a configurar una fuente de ingresos vital para estos entrevistados, así como para muchos actores que apelaron a este tipo de emprendimientos creativos con el fin de autogenerarse un empleo. De esta manera observamos la configuración de estos emprendimientos creativos en tanto estrategias económicas, laborales y productivas, que combinarían instancias de creación, producción artesanal, virtuosismo manual y subjetividad reflexiva, articuladas en la generación de nuevos proyectos. Proyectos que serían generados en un momento económico y social que reclamaba cambios.

Así como la crisis económica y social demandaba un cambio, demandaba mayor inserción e integración, así como un modelo social más justo y equitativo, estos actores veían en este momento la oportunidad de un cambio en sus vidas, y ese cambio vendría de la mano de la posibilidad de autogestión y del desarrollo creativo, poniendo en juego virtudes propias. Es decir que, tal como plantea Bourdieu (1998) la posibilidad de "hacer de la necesidad virtud" (1998: 318) tendría su

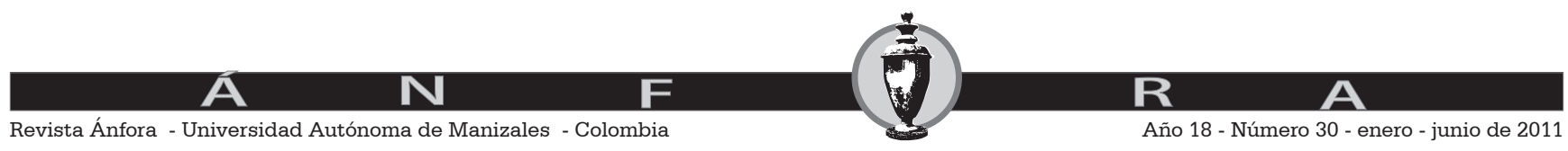


anclaje en este escenario, un escenario tan frágil, tan vulnerable, como potencial generador de posibilidades y oportunidades.

\section{Espacios 'informales' de circulación de productos}

Al pensar en el diseño, planteamos una modalidad de producción cultural, una práctica cultural que piensa y trabaja sobre bienes a ser incorporados a la cotidianidad, en un momento dado, en una historia dada, con sus lenguajes, sus conflictos y su inserción en la vida misma, en la producción y consumos de la sociedad. Podemos pensar el diseño como práctica cultural de la manera que lo plantea la autora Verónica Devalle, esto es: "además de considerarlo como disciplina y profesión moderna, lo entendemos, siguiendo la terminología empleada por Raymond Williams, como una 'práctica cultural' en el sentido de dialogar activamente con una determinada sociedad". (Devalle, 2009: 50).

En el caso analizado, los objetos diseñados por estos trabajadores dan cuenta de una realidad de producción que se inserta en un contexto social determinado, cuya estructura productiva apela a establecer segmentos de consumo, atendiendo a una lógica de producción distintiva, donde el diseño tiene un rol preponderante en el proceso productivo. En este caso, la producción de estos objetos remite mayoritariamente a un trabajo de tipo artesanal, en el cual predomina el cuidado por las formas, por la singularidad de cada producción, así como la búsqueda de una estética propia, singular. El detalle de cada producto, su 'artesanalidad' predomina por sobre la técnica industrializada de producción. Estos objetos se realizan generalmente pieza por pieza, y su formato y acabado suele ser individual, puesto que se aplican estilos y técnicas artísticas que buscan la obtención de bienes distintivos e individualizados, que puedan configurar 'lazos identitarios'.

Es decir, que estas creaciones buscan generar un vínculo más próximo con el consumidor usuario. Así, la producción de diseño independiente desarrollada por los jóvenes entrevistados no busca apelar a todos los consumidores, puesto que la misma no remite a una producción seriada, que busca la homogeneidad en los consumidores. Estos objetos no son ofrecidos mediante publicidades ni son presentados en las vidrieras de los shopping ${ }^{6}$, sino que buscan espacios de difusión como ser determinadas tiendas vinculadas al diseño o arte contemporáneo, como ser tiendas de museos de arte contemporáneo o espacios vinculados a la difusión cultural, como diversos centros culturales de Buenos Aires que han incorporado espacios de difusión de diseño independiente. Otro punto de comercialización que se plantea en la mayoría de los casos, es a través de páginas web7.

Una cuestión interesante a destacar en cuanto a la conformación de espacios de circulación de producciones de diseño independiente elegida por los jóvenes que se insertan inicialmente en estos emprendimientos, tiene que ver con la puesta en escena de ferias de diseño en diversos barrios de Buenos Aires. Las mismas han comenzado a tener lugar en la escena pública y en el
6 La mayoría de los objetos se comercializan en espacios no tradicionales de venta, a excepción de los objetos en cemento que pueden encontrarse en locales de shoppings de la Ciudad de Buenos Aires y GBA, por ser comercializados a través de una distribuidora que revende estos productos a locales de decoración.

7 Es importante destacar la relevancia que adquiere Internet como vía de difusión y comunicación para estos diseñadores, los cuales encuentran gran dificultad a la hora de difundir y comercializar sus productos, especialmente encuentran muy difícil la posibilidad de conseguir un comercio propio, debido a los costos de mantenimiento que éste implica. La página web a su vez permite establecer contactos con compradores de cualquier sitio del mundo, dando lugar a la posibilidad, como plantea la mayoría de los entrevistados, de exportar sus productos a diversos países.

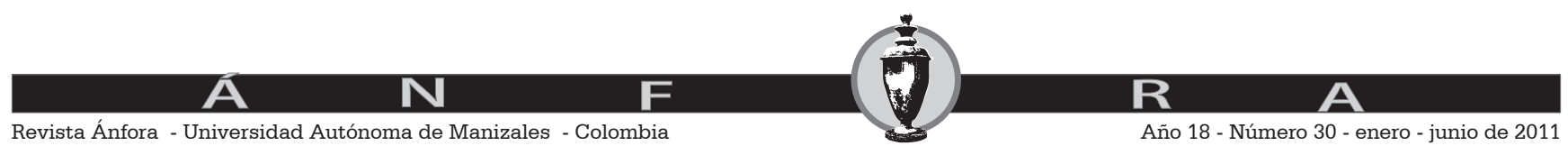


mercado, de tipo informal, a partir de 2001. La presencia de estas ferias de diseño independiente ha alcanzado en los últimos años una mayor visibilidad pública y una relevancia social en cuanto a la participación de jóvenes diseñadores y emprendedores que promueve en el mercado, si bien de tipo informal. En el caso del barrio de Palermo existen numerosas ferias de diseño que se disponen en bares, plazas, así como antiguas casas recicladas, dedicadas a fines artísticos o a la producción de diseño de indumentaria o de bienes de uso cotidiano.

Esto es, toda una performance de producciones de diseño independiente ha venido a plasmarse en espacios urbanos de la Ciudad de Buenos Aires. Como mencionamos, el barrio de Palermo es un exponente clave en este sentido performativo de producción y circulación de bienes de diseño, dando cuenta de este fenómeno en crecimiento del diseño independiente, como una modalidad de producción, de inserción y acción para numerosos jóvenes.

La configuración, tanto espacial como simbólica que promueve la producción de diseño independiente, se vincula con un crecimiento del denominado 'diseño de autor' en el mercado. Esta producción de diseño podemos decir que tiene como protagonistas, por un lado, a jóvenes emprendedores que han proyectado a través del diseño de bienes, una manera de insertarse de manera independiente o autogestionada en el mercado, al mismo tiempo que apelan a la creatividad para hacer "algo diferente", según ellos mismos plantean, y por otro lado, a consumidores que buscan una respuesta a sus demandas de mayor estetización e individualización en sus consumos, aportando a sus cuerpos, a sus maneras de vestir, de habitar, de vivir, un estilo de vida atravesado por una estética reflexiva y subjetiva.

En este punto es interesante reflexionar en relación a la conformación de estos consumos mayormente individualizados, los cuales predominan actualmente en un contexto de producción pos-industrial o pos-fordista, como plantean algunos autores. Esto es, si bien en las primeras décadas del siglo XX predominaba un modelo económico de producción de tipo fordista, basado en la producción industrial masiva, podemos decir que en los últimos años se ha orientado hacia una producción que comenzó a privilegiar aspectos simbólicos anteriormente no percibidos como determinantes de valor. Se desdibujaba así la primacía del propio quantum, de la producción en términos cuantitativos, para dar lugar al valor cualitativo de la producción, sea éste su valor figurativo, simbólico, funcional, dado por la propia intervención del diseño ${ }^{8}$. En este sentido, tal como plantea Renato Ortiz: "ya no sería más la producción en masa lo que orientaría la estrategia comercial de las grandes empresas, sino la exploración de los mercados segmentados (customized products)" (Ortiz, 1997: 25), esto es, crear, diseñar, comercializar productos orientados a segmentos bien definidos dentro del mercado. En este punto el diseño cumple un rol significativo en el mercado actual, orientado cada vez más a satisfacer consumos mayormente individualizados.
8 Tal como plantea Renato Ortiz (1997) en su trabajo Mundialización y cultura y retomando la expresión de Robert Reich, se trata del pasaje de una economía de "hign volume" a una de "high value" (Ortiz, 1997: 25), caracterizando justamente el desplazamiento de la primacía del volumen en la producción de los bienes por la valoración de los mismos, en términos simbólicos, en una dimensión cualitativa.

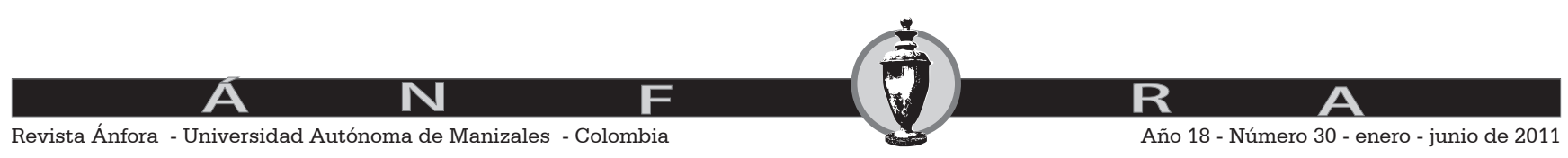




\section{La producción de diseño como configuración identitaria}

La sociedad de consumo contemporánea, tal como la analiza Featherstone (2000) da cuenta de un entramado visual que atraviesa la cotidianidad, los diferentes espacios de la vida, como la producción, el consumo, la circulación de bienes y servicios, el mercado, la calle, el espacio urbano, alimentando los diferentes ámbitos de la vida económica, social y cultural.

En este sentido, la cultura visual que predomina en el actual contexto de producción posfordista, al interior de escenarios globalizados donde el diseño tiene cada vez mayor protagonismo, da cuenta de una estética orientada a acompañar el proceso de impregnancia de lo visual, de los signos e imágenes circulantes, así como de las formas que acompañan la vida cotidiana de los sujetos, desde un punto creativo, interpelante, como modo de creación y no de anulación del sujeto. Se trata más bien de pensar la vida contemporánea como cargada de una impronta estética, sea en torno a los objetos, devenidos en signos como plantea Baudrillard, así como en este entorno de signos e imágenes que proliferan como parte del escenario visual (y virtual) propio de nuestra cultura contemporánea.

En este punto el diseño, como modalidad de producción y creación de formas para ser incorporadas en la vida cotidiana, a través de objetos, accesorios, mobiliario y demás, representa actualmente un valor agregado en la producción de bienes, sea por la configuración simbólica que tiene un peso predominante en la escena cotidiana, sea por la innovación que genera en cada uno de los bienes que interviene, actúa incorporando cierta impronta estética a través de las formas que crea, en la vida diaria. Así, el diseño se vincula a la idea de estetización, en tanto que se constituye como modalidad de creación simbólica, acompañando y realzando este proceso de producción y circulación de signos que impregnan el ámbito urbano.

De este modo, pensando en términos de la autora Leonor Arfuch, podemos pensar que los espacios urbanos, la calle misma como mundo del consumo "se convierte tempranamente en afirmación estética, donde el diseño, a su vez, encontrará en el arte una constante inspiración" (Arfuch, 2005: 190). De esta manera, el espacio urbano se presenta también como el escenario propicio para la contemplación estética, pero no una contemplación pasiva, sino una mirada que absorbe y se nutre de esta estética visual que delinea estilos de vida.

De esta manera la vida misma se nutre de diseño, puesto que el diseño mismo es cultura y la cultura hace a la conformación de la propia cotidianidad, de la vida misma, de la historia. Diseño y estética confluyen así en un todo simbólico que es la realidad de la vida cotidiana de la sociedad contemporánea. El diseño independiente como parte de esta cultura visual que nos nuclea, arraiga en la vida misma a través de los objetos, de su propio lenguaje, de su propia existencia, volviéndolos útiles, indispensables para la vida misma. Así la cotidianidad adquiere nuevas configuraciones en torno a esta constante

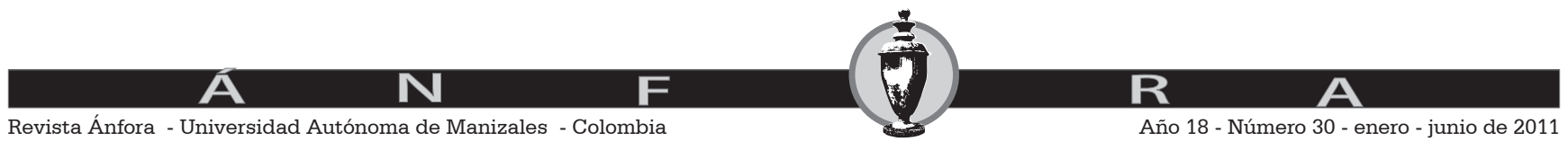


circulación de signos, en un sentido global, que ha irrumpido eficazmente los espacios de producción, circulación y consumo de bienes, el mercado, la comunicación, la interacción cotidiana, la propia socialización, en síntesis, la vida misma.

Podemos plantear que el diseño arraiga en la vida de los sujetos consumidores en torno a una búsqueda identitaria, a una búsqueda de estetización e impregnancia simbólica para conformar sus propios estilos de vida. Se puede afirmar en la actualidad que la vida misma se encuentra atravesada por el diseño, por la producción de diseño.

El diseño independiente ha generado en este sentido espacios de producción, circulación y consumo; ha configurado espacios de socialización y participación cultural, enmarcado en la producción cultural que el mismo recrea. Puesto que el diseño mismo se inserta en la trama de la cultura, se inscribe en lo social en tanto práctica cultural, construye bienes culturales, que trascienden el espacio social y los posiciona como reflejos de una historia, de un mercado y un modo de producción determinados, y acompaña justamente los cambios sociales, políticos, económicos de una sociedad y un período dados ${ }^{9}$.

De este modo cabe reflexionar nuevamente acerca de la función del diseño, de la creciente producción independiente de diseño generada en los últimos años, como elemento inherente a una economía creativa en constante expansión, a nivel local e internacional, alimentando un mercado ávido de bienes no masificados, que buscan de alguna manera reflejar subjetividades, de apelar a ellas, a partir de una elección enmarcada en un vínculo identitario a nivel consumidor-objeto. Pero esta posible identificación es uno de los múltiples sentidos identitarios que se configuran en torno al diseño independiente, puesto que se pueden establecer lazos identitarios a nivel productorconsumidor o diseñador-usuario, así como entre el productor/creador-objeto creado.

La identificación que produce el diseño de bienes entre el creador y su objeto da cuenta de una modalidad productiva subjetiva que permite al diseñador proyectarse en la producción que genera. Así, los jóvenes diseñadores que participan en el mercado productivo encuentran a través de sus propias producciones un espacio de autorrealización, una posibilidad de autogestión que pone en juego su subjetividad, una subjetividad creadora y transformadora, que lleva adelante no sólo la concreción de un emprendimiento económico y laboral, sino una instancia de auto-creación, como plantea Williams (2000), así como una instancia de configuración identitaria. En este sentido, tal como plantea la autora Arfuch, podemos pensar que:

El diseño cierra así el círculo, invistiendo el espacio de la vida privada, modelizando no sólo los cuerpos en su "apariencia", en la exhibición gestual y ritual cotidiana, sino interviniendo en cada uno de los registros de la experiencia,
9 En este sentido, Tomás Maldonado plantea esta correlación inherente entre la producción de diseño y las condiciones políticas, económicas y sociales en que la misma se asienta. Podemos ver en el siguiente pasaje el reflejo de esta cuestión, al hablar del contexto que caracterizó la producción generada en la Bauhaus como en directa relación con sus condiciones históricas: "No es casual que la República de Weimar y la Bauhaus tengan la misma fecha (y lugar) de nacimiento, y la misma fecha de desaparición (1933). También su periodización presenta un paralelismo sorprendente y apenas se puede resistir la tentación de establecer un nexo casual entre ambos desarrollos." (Maldonado, 1993: 46) La cita, si bien continúa estableciendo los paralelos entre una y otra instancia, lo planteado nos permite ver en cierta forma esta incidencia mutua, estos paralelismos entre producción de diseño y sus condicionantes históricosociales.

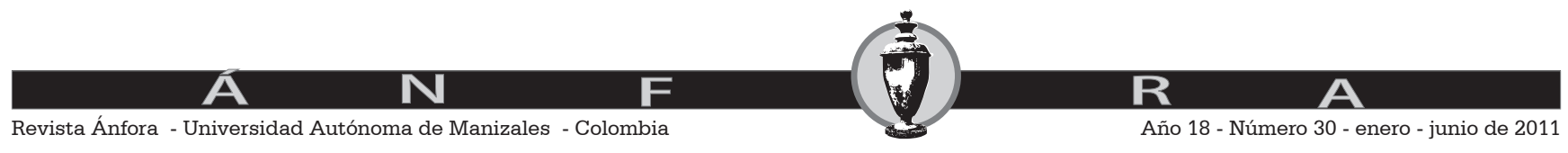


en ese conglomerado de imágenes dispersas, sensaciones, vivencias, cuyo anclaje en algún punto reconocible llamamos "identidad". Es en este sentido que puede hablarse del diseño como configurador de identidades (culturales, grupales, generacionales, etc.) en tanto está involucrado en los procesos de subjetivación, en una serie de prácticas sociales que trazan espacios de pertenencia e identificación". (2005: 211-212).

De este modo, la configuración identitaria que promueve el diseño en torno de la intervención que produce en lo social, actúa construyendo y otorgando identidad, por un lado, al sujeto creador, en este caso los jóvenes diseñadores independientes, al plasmar en sus producciones una subjetividad creativa que permite el desarrollo de bienes culturales con los cuales se identifican y auto-realizan, y que interpelan por otro lado, identitariamente, a los consumidores de estos bienes, enlazando así al sujeto creador con su objeto creado, $\mathrm{y}$ al sujeto productor con el sujeto consumidor. El diseño podemos decir que constituye espacios de pertenencia, de socialización, de creación reflexiva y de configuración de relaciones identitarias.

Esta posibilidad de inserción que genera la producción de diseño independiente en relación a numerosos jóvenes emprendedores, permite construir un espacio de acción desde lo más genuino, desde una subjetividad reflexiva que los conduce a la acción, a la producción y a la socialización, si bien desde espacios informales productivos, alcanzan al mismo tiempo un desarrollo personal dado por su potencialidad creadora y capacidad transformadora.

\section{A modo de reflexión}

Este trabajo ha permitido plasmar una aproximación analítica a los modos de participación que asumen actualmente en la vida económica y productiva los diseñadores independientes de objetos, específicamente a partir de la crisis del 2001 en Argentina, la cual se ha constituido como un punto 'bisagra' para dar lugar a la configuración de nuevas prácticas laborales, productivas, vinculadas a los emprendimientos propios y a la autogestión.

Se trató de dar cuenta así de las modalidades que se plantean y ponen en juego en relación a este fenómeno en crecimiento, denominado diseño independiente.

Como conclusiones finales, podemos plantear que la actual producción de diseño independiente ha dado lugar a la participación de numerosos jóvenes en el mercado laboral, si bien en muchos casos a partir de una inserción informal (en muchos casos trabajando sin seguridad social o comercializando sus producciones en espacios informales, como bares, plazas o ferias), esta modalidad productiva se ha basado en una lógica de trabajo autogestionada,

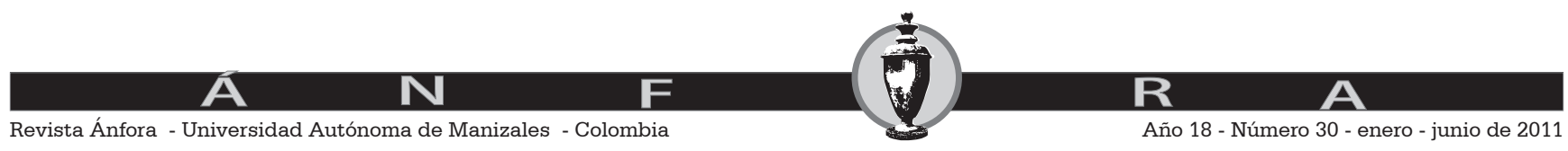


la cual implica la puesta en juego de habilidades y potencialidades propias de los trabajadores.

También podemos plantear que si bien no todos los actuales diseñadores son diseñadores de formación (no todos han estudiado carreras de diseño), sí se piensan como creadores, productores y hasta diseñadores de manera experimental, empíricamente. Por otra parte todos los entrevistados coinciden en el auge y desarrollo del diseño en Argentina en los últimos años y si bien les cuesta ubicarse como actores participantes de este fenómeno, al mismo tiempo consideran que producen determinados bienes diferenciados, distintos a lo visto en el mercado, lo cual los posiciona, con mayor o menor aceptación, en el espacio del diseño y a partir de éste, en el espacio social.

En este sentido, la producción de objetos creativos, enmarcados en un contexto de incentivo a la producción nacional, constituye el resultado de la combinación de innovación, creatividad, exploración, deseos puestos en juego, articulados con técnicas artísticas que le brindan un sentido más artesanal, o (¿por qué no?) más humano, remitiendo a técnicas preindustriales de producción, evocando a una producción artística y cultural que plasma en el objeto una identidad propia, un proceso identitario que confluye, tanto en la instancia productiva como en el consumo mismo.

Por otro lado, en un sentido más amplio, podemos pensar que el campo cultural se halla atravesado por múltiples manifestaciones expresivas, entre ellas la producción de bienes culturales que permiten instalar determinados significados, signos y símbolos propios de estos tiempos, de una posmodernidad en cambio constante, o paradójicamente, cuya constante ha pasado a ser el cambio continuo, al interior de un escenario globalizado en el cual estos actores construyen su espacio de acción. Hablamos de un espacio de acción emergente justamente en un momento de crisis, de cambio, que dio lugar a estas producciones autogestionadas como consecuencia de una necesidad de cambio, de búsqueda de espacios de participación. Hablamos de un espacio constituido desde la propia fragilidad y vulnerabilidad como es un momento de crisis, que lleva a cuestionarse a indagar por nuevos espacios y nuevas modalidades de producción en sentido de acción.

A su vez, es importante destacar que es el diseño en la actual sociedad de consumo, junto a otros factores como la publicidad y el marketing, quienes impulsan la elección de determinados bienes, posesiones, consumos, que van a delinear subjetividades, estilos de vida. Así, el diseño viene de alguna manera a configurar identidades, como plantea Arfuch (2005), instituyendo una modalidad de construcción identitaria en la vida cotidiana, en este caso, desde la producción cultural.

La producción independiente de diseño busca en este sentido alcanzar nuevas significaciones no sólo en el plano económico y productivo, sino en la trama misma de la cultura, generando nuevas configuraciones en el espacio urbano, nuevas posibilidades de producción y acción, entendidas como prácticas culturales que emergen y alcanzan mayor visibilidad en la escena

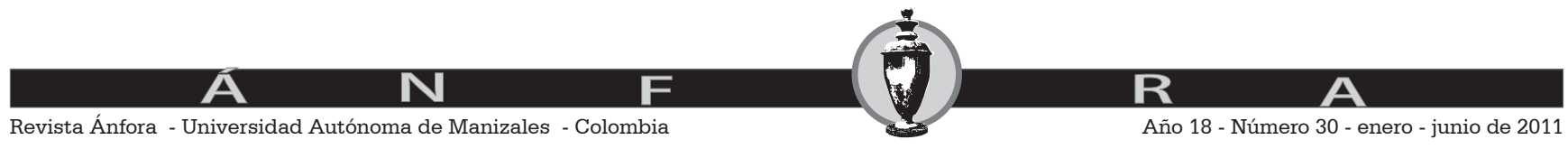


pública a partir del contexto de crisis del 2001. Entendido como un período de inicio de nuevos emprendimientos, que vienen, de alguna manera, a instalar la presencia de nuevos actores, como los jóvenes diseñadores independientes, que buscan autogestionarse un espacio productivo desde la práctica del diseño, así como alcanzar un espacio de inserción económica, laboral y productiva desde una práctica cultural, como es el diseño de bienes, aportando así a la construcción simbólica de la vida cotidiana y a la configuración de identidades sociales. 


\section{Referencias bibliográficas}

Arfuch, Leonor, Chaves, Norberto y Ledesma, María (2005) Diseño y comunicación: teorías y enfoques críticos. Buenos Aires. Paidós.

Bourdieu, Pierre (2002) Cuestiones de sociología. Madrid. Istmo.

Bourdieu, Pierre (1998) La distinción. Madrid. Taurus.

Bourdieu, Pierre (1992) El sentido práctico. Madrid. Taurus.

Correa, María Eugenia (2009) "El fenómeno del Diseño independiente en la Ciudad de Buenos Aires: Análisis de la conformación de un nuevo trabajador cultural en la escena local". Tesis de Maestría en Sociología de la Cultura, IDAES-UNSAM.

Correa, María Eugenia (2007) El diseño como nueva modalidad de producción cultural: aproximación al análisis de los jóvenes diseñadores artísticos de la Ciudad de Buenos Aires. En VII Jornadas de Sociología. Facultad de Ciencias Sociales. UBA. Buenos Aires.

Devalle, Verónica (2009) La travesía de la forma: emergencia y consolidación del diseño gráfico (1948-1984). Buenos Aires. Paidós Estudios de Comunicación.

Featherstone, Mike (2000) Cultura de consumo y posmodernismo. Buenos Aires. Amorrortu.

Filmus, Daniel (Comp.) (1999) Los noventa: política, sociedad y cultura en América Latina y Argentina de fin de siglo. Buenos Aires. Eudeba.

Heskett, John (2002) El diseño en la vida cotidiana. Barcelona. Gustavo Gili.

Lacarrieu, Mónica y Álvarez, Marcelo (Comps.) (2998) La (indi)gestión cultural: una cartografía de los procesos culturales contemporáneos. Buenos Aires. La Crujía.

Lash, Scott y Urry, John (1997) Economías de signos y espacios: sobre el capitalismo de la posorganización. Buenos Aires. Amorrortu.

Maldonado, Tomás (1993) El Diseño Industrial reconsiderado. Barcelona. GG.

Ortiz, Renato 81997) Mundialización y cultura. Buenos Aires. Alianza.

Svampa, Maristella (2003) Desde abajo: la transformación de las identidades sociales. Buenos Aires: UNGS - Biblos.

Svampa, Maristella (2005) La sociedad excluyente: la Argentina bajo el signo del neoliberalismo. Buenos Aires. Taurus.

Wortman, Ana (Coord.) (2003) Pensar las clases medias: consumos culturales y estilos de vida urbanos en la Argentina de los noventa. Buenos Aires. La Crujía.

Williams, Raymond (2000) Marxismo y literatura. Barcelona. Península/ Biblos.

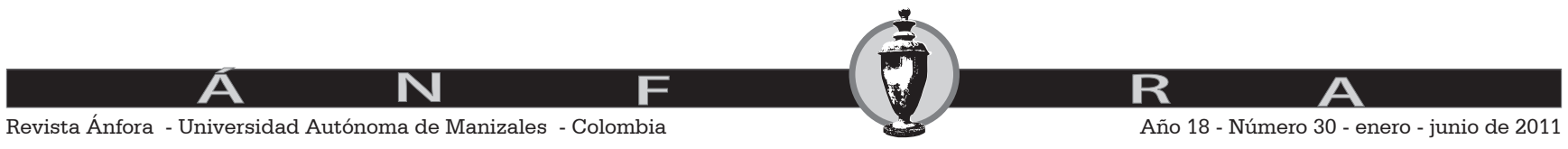

